\title{
A SELF-MANAGEMENT APPROACH TO REDUCING AIDS RISK IN SEXUALLY ACTIVE HETEROSEXUAL COLLEGE STUDENTS
}

\author{
Patricia A. Horn \\ Thomas A. Brigham \\ Washington State University
}

\begin{abstract}
This study investigated the effectiveness of a self-management skills training (SMST) program in modifying at-risk sexual behaviors among a group of 51 college-aged heterosexual, sexually active, males and females. The frequency of condom use and related responses were self-monitored before, during, and after participation. In addition, pre- and post-test treatment measures were used to analyze attitudes and beliefs related to issues such as risk of HTV and AIDS, sexual communication skills, and condoms. The SMST program focused on identifying antecedent variables, planning appropriate response sequences, and arranging positive consequences. These skills were then practiced in the program sessions and via home work assignments. Results showed significant increases in reported condom use, condom purchase.and in condom-use dialogue with sexual partners. The findings of this study may be useful in developing effective intervention programs to reduce the risk of AIDS on college campuses.
\end{abstract}

Until recently, little data existed to characterize the prevalence of the AIDS epidemic on college campuses or, in a more general sense, within the late-adolescent population in the United States. However, a 1989 study by the Centers for Disease Control and the American College Health Association found that 2 out of every 1,000 university students tested were HIV-positive with a lower fraction displaying other characteristics from AIDS symptoms to full blown AIDS (Gayle et al., 1990). When these data are extrapolated to a campus with 15,000 students, the infection rate corresponds to 1 student with AIDS, 2 to 7 with AIDS-related symptoms, and 25-35 with HIV infection (Biemiller, 1989). Given the increase in the heterosexual transmission of HIV (CDC, 1993), these statistics probably underestimate the longterm problem constituted by AIDS within this age group or on college campuses. The college-aged population, for a variety of reasons, is especially vulnerable to HIV infection. Most students are, for the first time, actively experimenting with behaviors that place them at risk, such as multiple sexual partners, use of drugs and alcohol

\section{AUTHOR'S NOTE:}

This research was supported in part by funding from the College of Liberal Arts, the Division of Student Affairs, and the Graduate School at Washington State University. The authors also wish to acknowledge the crucial contributions of other research team members: Darells Koonce, Sarah Zemke, Nancy Thomas, Bo Gilbert, Nancy Olson, and Chad Barnett. Address correspondence related to this article to: T.A. Brigham, Department of Psychology, Washington State University, Pullman, WA 99164-4820. A revised version of the curriculum and an instructor's guide may be obtained for copying costs. 
HORN \& BRIGHAM

mixed with sexual activity, and failure to practice "safer sex" by condom use. The extent of these at-risk behaviors within this age group has been well-documented in other studies, including those by Bowler, Sheon, D'Angelo, and Vermund (1992), Strunin and Hingston (1987), Chesney (1993), Rehnberg (1991), Catania et al. (1992), Blonna, Hayden, and Milcetic (1991), Baldwin and Baldwin (1988), and Baum and Weltman (1989).

As an outgrowth of concerns about the vulnerability of late-adolescents and young adults, a number of AIDS risk-reduction programs and studies have been conducted. The first efforts involved basic AIDS information presentations. After an intensive AIDS education campaign directed at adolescents in San Francisco, a follow-up study conducted 1 year later indicated that sexually active youth continued to have multiple sex partners and did not substantially increase their use of condoms (Kegeles, Adler, \& Irwin, 1988). Orr et al. (1992), in a study of risky sexual behaviors among adolescents, concluded that knowledge about AIDS and sexually transmitted diseases (STDs) did not affect condom use, but that other risk factors such as drugs or alcohol had a negative effect on use. Similar conclusions were reached in other research by Baldwin and Baldwin (1988), Foster (1988), and Goertzel and Bluebond-Langner (1991). Despite all of the attention given to AIDS and the nation-wide dissemination of AIDS-related information, Becker and Joseph (1988) concluded that AIDS education had little impact on behavior within the "potentially vulnerable adolescent and young adult heterosexuals."

Because education and informational messages have been shown to be ineffective, psychologists and other professionals have recommended a variety of intervention approaches, focused specifically on altering behavior instead of solely imparting knowledge. Much of the early AIDS prevention research using behavioral intervention was with high-risk groups (often gay men) located in or near the epicenters of the AIDS epidemic; and for these specific populations where behavioral outcomes have been measured, significant short-term behavior changes were observed (Coates, 1990). In many of these studies involving the homosexual community, factors identified as being associated with behavior change include selfefficacy for low-risk behavior (McKusick, Horstman, \& Coates, 1985), awareness of personal vulnerability, reduced substance use, and perceptions that low-risk behavior is an acceptable norm for the individual's peer group (Kelly et al., 1990). A recent summary of studies by Chesney (1993), confirm that these same factors are associated with behaviors in the general heterosexual population, with self-efficacy, perceptions of peer norms, and attitudes about condoms being associated with lowrisk behaviors.

Research that specifically addressed condom use has shown that knowledge about the proper use and effectiveness of condoms in preventing STDs was related to safer sex behavior (Blonna et al., 1991; Sacco, Levine, Reed, \& Thompson, 1991; Shulkin et al., 1991). In the study by Sacco et al., it was concluded that self-control factors accounted for most of the variability in past and intended purchase, carrying, and keeping of condoms. Similarly, a study of young, single, inner-city women by Hobfoll, Jackson, Lavin, Britton, and Shepherd (1994) demonstrated that an intervention program focused on AIDS-specific knowledge and skills, including assertiveness and self-efficacy, could be effective in promoting safer sex behaviors. 


\section{REDUCING AIDS RISK}

Many of these studies cited behavioral interventions fall within the model of "self-management," described as the "application of behavior analysis principles and procedures to modify the behavior/environment interactions of the individual by the individual" (Brigham, 1982). This model has been proven effective in addressing other social or health-behavior problems (such as cigarette smoking or obesity) and has been used as a component of interventions that combine education, assertion training, and peer support with assistance in behavioral self-management (Kelly, St. Lawrence, Hood, \& Brasfield, 1989). Kelly and St. Lawrence (1987) define selfmanagement as including the "identification of stimulus antecedents to high-risk encounters and rearranging environmental circumstances to reduce the likelihood of such encounters."

This focus by Kelly and St. Lawrence is similar to Brigham's model of selfmanagement behavior, in which an analysis of self-control problems plays an important role in selecting appropriate behavior interventions. In this analysis, the presence of a self-control problem usually involves a difference between immediate and delayed consequences of a response. For AIDS prevention, as an example, the immediate consequences of choosing to use a condom is viewed against the delayed consequences of not using condoms. Whereas the immediate consequence of not using them is often reported to be positive in terms of enhanced sensation, the delayed consequence is potentially major (infection by HIV) but with a perceived very low risk. If self-management skills are to be emphasized in an AIDS prevention program to increase the frequency of low-risk behavior, then "the environment must be analyzed and restructured to make both the occurrence and the reinforcement of the response more probable" (Brigham, 1982).

The approach of teaching appropriate self-management skills to individuals may be termed "Self-Management Skills Training" or SMST (Brigham, 1989). SMST is consistent with the conceptual model of AIDS risk-reduction proposed by Fisher and Fisher (1992), who stressed that there are three fundamental determinants of reducing risk: Providing information about AIDS transmission and prevention, providing motivation to reduce the risk, and providing the behavioral skills for performing acts involved in risk reduction. This model emphasizes the need to address protective as well as risk factors, and also suggests a linkage between cognitive and behavioral approaches as part of a comprehensive risk-reduction strategy.

The purpose of this study, therefore, was to examine the effectiveness of SMST in reducing the risk of AIDS infection among sexually active, multiple-partnered, heterosexual, college students. Analysis focused on behavioral changes related to condom use and other "safer sex" practices, following participation in a three-session program that emphasized the SMST approach. Objectives included an evaluation of the program's effectiveness, using assessment instruments and weekly self-monitoring forms that surveyed sexual history and behavior, specific attitudes towards AIDS risk and condom use, and sexual communication skills. Based on prior research, it was hypothesized that SMST would be effective in increasing the frequency of condom use as well as increasing the condom-use dialogue between subjects and their sexual partners. 


\section{HORN \& BRIGHAM}

\section{Method}

\section{Subjects}

A large pool of potential subjects was solicited from Washington State University residence halls, sororities, and fraternities, and were then asked to fill out the Sexual Behavior Background Survey (SBS). After reviewing their responses on the SBS, those students who reported being sexually active, multiple-partnered heterosexuals using condoms less than $40 \%$ of the time were contacted and asked to participate. From this pool of students, 60 subjects were eventually selected. Although all 60 agreed to participate, only 51 actually completed the pre-test and attended the first training session, and of these only 46 subjects completed the entire study. The initial 51 participants included 30 females and 21 males, with a mean age of 20 years. All subjects reported being sexually active for some time (a mean period of over 4 years) and reported themselves to be heterosexuals with a moderately high level of sexual activity. The human subjects protocol used in this experiment met all APA standards and was approved by the university's Institutional Review Board (IRB).

\section{Experimental Design and Methods of Data Analysis}

The research used a group replication with repeated measures design which resembled the multiple time series design described by Campbell and Stanley (1963). It is also similar to a multiple baseline across groups design, but the introduction of manipulations is based on time rather than the stability of the baselines. In addition, several questionnaires were administered pre- and post SMST in order to evaluate the effects of the program on the knowledge and attitudes of the participants. The 51 subjects were pre-tested and began weekly reports on their sexual activity at approximately the same time. At the time of screening and subject selection, the qualifying subjects were randomly assigned to six different classes, consisting of three classes of approximately 9-11 subjects each, for each of two training periods. Group A, with three classes, met during weeks 3 through 5 of the study, while Group B (again with three classes) met during weeks 6 through 8 . Using the weekly reports, it is possible to relate changes in behavior to participation in the program, and experimentally establish whether the program was responsible for any observed changes in behavior.

\section{Assessment Instruments}

One instrument, the SBS, was used to obtain initial background information and to screen individuals as potential subjects; and three additional instruments were used to obtain beliefs and attitudes related to AIDS, condom use, and sexual communication with partners. These last three instruments were administered to all subjects twice. The first testing took place as a pre-test prior to any treatment and then again as a post-test after each group had received the SMST sessions. Additionally, subjects were asked to report on a weekly basis throughout the study 


\section{REDUCING AIDS RISK}

their ongoing behavior patterns regarding frequency of intercourse, condom use, sexual communication with partners, and number of partners each week. Each of the five instruments is briefly described below.

Sexual Behavior Self-Monitoring Form (SBSMF)

Following Kelly et al. (1989), the primary dependent variable in the present study was a self-monitored measure of sexual activity and condom use. Research shows that clearly defined salient responses that are reported on a daily or weekly basis can be very accurately self-monitored (Barlow, Hayes, \& Nelson, 1984). A weekly reporting format was used to increase sensitivity and decrease reporting errors. This new instrument, with only six questions, was designed to provide a record of self-reported sexual behaviors each week until the end of the study (coinciding with the end of the semester). Because of the importance of this instrument in assessing changes in behavior, as opposed to attitudes, an abbreviated form of the six questions is provided:

Q1. (Frequency) In the past week, approximately how many times have you had sexual intercourse?

Q2. (Condom Use) In the past week, approximately how many times have you used a condom?

Q3. (Partners) How many partners have you had sex with in the past week?

Q4. (Alcohol) Has drug or alcohol use been a factor in your decisions to use or not use condoms?

Q5. (Discussion) How many times have you had sexual intercourse during the past week when you discussed condom use with your partner?

Q6. (Acquisition) How many times in the past week have you purchased or picked up free condoms?

Finally, a comments section was added to allow subjects to report observations about experiences related to their sexual behavior.

Sexual Background Survey (SBS)

This instrument represents a combination of portions of other existing instruments, including the Burroughs Wellcome STD Risk Assessment and the Foster's AIDS Belief Survey. From each of these, questions that pertain to a subject's background, sexual preferences, level of sexual activity, use of condoms, and extent of at-risk behaviors were compiled into this summary survey. In its final form, it poses a set of 30 questions, including key screening items such as the following:

- "How would you characterize your sexual activity level during the past year?"

- "How would you describe your sexual orientation?" "How many partners have you had sex with in the past year?" 


\section{HORN \& BRIGHAM}

- "How would you describe your sexual identity (monogamous, primarily monogamous, multiple partners)?"

- "What percentage of the times that you have had sexual intercourse during the past month have you used a condom?"

Condom Attitude Scale (CAS) (Sacco, Levine, Reed, \& Thompson, 1991)

This is a 57-item questionnaire using a 7-point personal-belief scale that measures eight specific factors and subscales: Interpersonal Impact (CII), Effect on Sexual Experience (CE), Self-Control (CSC), Global Attitude (CGA), Perceived Risk (CPRSK), Inhibition (CIN), Promiscuity (CPROM), and Relationship Safety (CRS). Each of these factors, and the associated questions, has been demonstrated to measure distinct aspects of condom attitudes, with subscale scores that are well correlated with different aspects of condom use or intended use. Both the composite score as well as the eight separate subscale scores can be useful in developing an overall measure of attitudes towards condoms, in predicting condom use within specific subgroups, or in predicting different condom use behaviors (such as buying or carrying a condom). Cronbach analyses on the eight subscales displayed the following values: 0.90 for CII (11 items); 0.89 for CE (10 items); 0.87 for CSC (9 items); 0.62 for CGA (9 items); 0.84 for CPRSK (6 items); 0.76 for CIN (4 items); 0.81 for CPROM (3 items); and 0.79 for CRS (5 items).

Sexual Communication (SC) (Catania et al., 1989)

This 10-item instrument was used to provide information on sexual communication between the subjects and their potential and primary sexual partners. Sexual communication skills have been found to be significantly correlated with condom use in prior studies. The instrument consists of two subscales: One, SCNOW, focusing on the current or primary sexual partner (7 items, Cronbach alpha $=0.77)$; and the other, SCNEW, related to attitudes concerning future partners (3 items, Cronbach alpha $=0.67)$. Each question uses a 4-point Likert scale, ranging from strongly disagree to strongly agree.

Foster's AIDS Belief Survey (FABS) (Foster, 1988)

This survey, in its original form, is a 24-item questionnaire measuring six specific beliefs related to AIDS and condom use. Because Foster's research indicated that only three of the six belief factors were correlated with intent to use condoms, Rehnberg (1991) condensed this instrument by selecting the 12 questions associated with the three factors, including perceived Self-Efficacy (FSE) for condom use, reported Intent (FI) to use condoms, and perceived Vulnerability (FV) to AIDS. Each question is scored on a 7-point Likert scale and is nonspecific regarding gender. A Cronbach's alpha analysis performed on each subscale resulted in values of 0.54 for $\mathrm{FV}, 0.87$ for FSE, and 0.84 for FI. 


\section{REDUCING AIDS RISK}

\section{Self-Management Skills Training Program}

All subjects were given three 2-hour sessions consisting of a combination of group discussion, skill modeling, and behavioral rehearsal, all related to the goal of increasing condom use and avoiding unsafe-sex practices. The sessions focused on the subjects' behavior and environment interactions and the role that these interactions may play in reducing the risk of AIDS.

Session I began with establishment of ground-rules concerning participation and the confidentiality of results. During this session, the initial discussion centered on personal perceptions of AIDS risk, ways of altering behavior to reduce the risk, and problems associated with these behavioral responses. This introduction led to a question period devoted to developing the importance of planning for increasing the frequency of condom use or altering any at-risk behavior patterns. The questions and discussion were guided towards environmental variables such as condom availability as well as environmental antecedents such as alcohol or drug use before sex.

Through discussion and role playing, the group then explored interpersonal aspects of sexual behavior, including the need for communicating and goal-setting with sexual partners and involving them in sexual decision-making. A communication exercise was included to facilitate the group members' ability to discuss sexually explicit vocabulary with each other. Emphasis was placed on finding fun ways to feel comfortable talking about topics of a sexual nature.

With the group made up ofboth males and females, subjects had an opportunity to practice a variety of challenging role plays which present difficult situations that may come up in real-life settings. Subjects learned to use different problem-solving techniques and assertiveness strategies that could then be adapted to their personal lives. Finally, subjects developed an Individual Action Plan (IAP) to assess and improve their own behavior/environment interactions. Specific attention was given to the concept of "monogamous relationships," differentiating these from "serial monogamy."

The session concluded with a review of the material covered and specific homework assignments including encouragement to purchase condoms and to begin a dialogue with a current or potential partner about incorporating safer sex practices.

During Session II, the group began by reviewing what happened during their homework assignment experiences. Group feedback and positive reinforcement were given as subjects discussed their initial efforts at developing their own personal "proactive plan." Real-life situations which were especially challenging for subjects were role-played within the group format, again seeking win-win outcomes. Two of the role play exercises in this session were bringing up the topic of condom use with a potential partner and what would you do if a partner says no to using a condom? Participants were given a topic to act out and then coached by the group leaders if they had difficulties. After each participant had role played, the topics and strategies were discussed and additional approaches modelled. Improving both assertiveness and communication skills was emphasized as key elements in reducing AIDS risk.

To increase subjects' knowledge of and comfort with the use of condoms, "hands-on" exercises were conducted during Session III in which each subject had the opportunity to open condoms, to place them on their hands and other objects, to 


\section{HORN \& BRIGHAM}

examine sensitivity, and to compare several different brands of condoms. Following this exercise, each subject identified his or her preferred brand in a consumer-surveytype rating.

Discussion also addressed positive ways a condom can be incorporated prior to the act of intercourse. In keeping with the idea of an individual proactive plan, subjects were asked to identify where they could readily acquire condoms and where they planned to place them in their environments that would increase the chances of condom use. As in Session I, one objective of the self-management approach was to show that this sometimes frightening subject matter can be approached in a lighthearted, yet serious way (as long as one is proactive and not reactive), that, in fact, to make personal safety and health decisions need not be a painful process for oneself or one's partner. Group members were then asked to review with one another their own plans for "Where do I go from here?" Each subject was requested to address any barriers or obstacles that he or she may foresee and ask other group members for suggested strategies in overcoming these potential difficulties. Before the session ended, subjects were given the post-test and urged to continue submitting their weekly reports.

\section{Results}

For the purpose of analysis, the data may be divided into three categories. The first data set represents the responses to the SBS, which provides a description of the sexual history and demographics of the subjects. The second is the weekly measures of sexual activity and behavior, as reported by each participant on the SBSMF. The pre- and posttreatment measures of attitudes and beliefs related to AIDS, condom use, and sexual communication make up the third data set.

\section{Evaluation of Sexual Background Survey Results}

The SBS served, not only as the instrument for subject screening and selection, but also as a primary source of information concerning subject demographics, sexual background, and sexual behavior. In general, the subjects constituted a relatively narrow age group ranging from 18 to 28 years, with a median age of 20 years and a standard deviation of only about 2 years. The typical subject was either a freshman or sophomore, and lived in a residence hall, or within the Greek system. As previously noted, 30 of the 51 were female, and all reported themselves heterosexual in sexual preference.

In terms of sexual activity, most subjects categorized his or her activity level as moderate to moderately high, as substantiated by a mean intercourse frequency of nearly 11 times per month. Subjects had an average of over three different sexual partners during the past year, with 41 of the subjects indicating that they did not consider themselves to be "monogamous." Of the 10 subjects who claimed monogamous relationships, all 10 indicated that they had more than one partner during the past year.

Few subjects showed any regular patterns of safe sex behavior. The mean condom use reported was 0.40 times during the past month, compared with a mean 
intercourse frequency of 10.80 times. The number of times the use of condoms had even been discussed was equally low $(\mathrm{M}=0.34)$. Finally, a monthly mean of 0.47 of casual sexual encounters was reported by the group.

\section{Evaluation of Weekly SBSMF Results}

\section{Data Compilation and Variable Definition}

Before any inferential tests were performed, the data from the SBSMF were sorted by question and week, and appropriate descriptive statistics were calculated. This initial analysis revealed the need to define an additional variable, use/frequency, to examine the trend in condom use throughout the study. Although question 2 asked for the number of times condoms had been used during the previous week, as an absolute number it was meaningful only when compared to the frequency of intercourse. Therefore, the ratio of condom use to intercourse frequency was calculated and defined only when the value of frequency was non-zero. Because there were weeks in which a subject reported no sexual intercourse, the overall sample size was reduced to approximately $60 \%$ of that for the other variables.

In the initial data review, it was also decided to eliminate question 4 ("Has the use of drugs or alcohol been a factor in your decisions to use or not use condoms?") from further analysis, because so few of the responses (13 out of nearly 400) had been affirmative.

\section{Comparison of Pretreatment and Posttreatment Periods}

To evaluate the effectiveness of the SMST sessions in producing positive behavioral responses, the data sets for both groups were divided into two time periods: Baseline (pretreatment) and instruction and follow-up (posttreatment). The baseline period was defined as consisting of all weeks prior to the first class session, plus the week of the first session (the timing of the report submissions was such that the first session was assumed to have no influence on the report for that week). This resulted in baseline periods of weeks 1 through 3 for Group A, and weeks 1 through 6 for Group B.

To perform paired samples testing, the pretreatment responses for each subject were averaged, and this average was compared to the mean posttreatment responses from the same subject. Subjects who dropped out of the study at some point during the 9 weeks were eliminated from these tests. Similarly, the means were based only on the weekly responses submitted, and therefore the sample sizes are reduced for subjects who may have missed one or two reports. The means for variable use/frequency also exclude any missing data, as well as data from any weeks when no intercourse occurred. If a subject did not report intercourse for any week during either the pre- or posttreatment period, then that subject was not included in the paired test for use/frequency.

Tests were performed separately for each group and then for the combined data set. With Group A, significant differences (at an a-level of 0.05) between pre- and posttreatment means were produced for variables frequency, acquisition and 
use/frequency (p-values of 0.023, 0.013, and 0.013). In Group B, there were significant differences in the means for variables frequency, discussion, acquisition and use/frequency (p-values of 0.002, 0.002, 0.018, and 0.005). Finally, for the combined data set (Group A plus Group B), variables frequency, discussion, acquisition and use/frequency showed significant increases in mean responses ( $p$ values of $0.000,0.049,0.001$, and 0.000$)$. Table 1 provides a summary of descriptive statistics and the results of the paired samples t-tests for the combined Group A and Group B data.

Table 1. Groups $A$ and $B$ Combined: Paired t-test Results for Total Pretreatment Versus Posttreatment Responses

\begin{tabular}{|c|c|c|c|}
\hline Questions & \begin{tabular}{l}
\multicolumn{1}{c}{$x$} \\
Statistics for \\
Pretreatment
\end{tabular} & $\begin{array}{l}\text { Statistics for } \\
\text { Posttreatment }\end{array}$ & $\begin{array}{l}\text { Alt. Hypoth.; } \\
\text { Test stat.; } \\
\text { p-value; } \\
\text { df }\end{array}$ \\
\hline $\begin{array}{l}\text { Question 1: Frequency } \\
M= \\
n=\end{array}$ & $\begin{array}{c}2.059 \\
45\end{array}$ & $\begin{array}{c}1.958 \\
45\end{array}$ & $\begin{array}{l}t=-\mathbf{0 . 3 8 9} \\
\mathbf{E}=\mathbf{0 . 6 8 0} \\
\mathbf{d f}=440\end{array}$ \\
\hline $\begin{array}{l}\text { Question 2: Condom Use } \\
M= \\
n=\end{array}$ & 0.267 & $\begin{array}{c}0.678 \\
45\end{array}$ & $\begin{array}{l}t=-3.788 \\
E=0.000 " \\
\text { df }=44\end{array}$ \\
\hline $\begin{array}{l}\text { Question 3: Partners } \\
M= \\
n=\end{array}$ & $\begin{array}{c}0.602 \\
45\end{array}$ & $\begin{array}{c}0.643 \\
45\end{array}$ & $\begin{array}{l}t=-0.708 \\
E=0.483 \\
\text { df }=44\end{array}$ \\
\hline $\begin{array}{l}\text { Question 5: Discussion } \\
M= \\
\mathbf{n}=\end{array}$ & $\begin{array}{c}0.333 \\
45\end{array}$ & $\begin{array}{c}0.477 \\
45\end{array}$ & $\begin{array}{l}t=-1.689 \\
E=0.049 * \\
\text { df }=44\end{array}$ \\
\hline $\begin{array}{l}\text { Question 6: Acquisition } \\
\quad M= \\
n=\end{array}$ & $\begin{array}{c}0.128 \\
45\end{array}$ & $\begin{array}{c}0.286 \\
45\end{array}$ & $\begin{array}{l}t=-3.287 \\
E=0.001 " \\
\text { df }=44\end{array}$ \\
\hline $\begin{array}{l}\text { Use/Frequency: } \\
\qquad \begin{array}{l}\mathbf{n}= \\
n\end{array}\end{array}$ & $\begin{array}{c}0.234 \\
35\end{array}$ & $\begin{array}{c}0.498 \\
35\end{array}$ & $\begin{array}{l}t=-3.762 \\
E=0.000 " \\
\text { df }=34\end{array}$ \\
\hline
\end{tabular}

* Significant at the $a=0.05$ level

* Significant at the $a=0.001$ level 
The changes in the weekly mean percentage of condom use by all 51 subjects in Groups A and B, as a function of baseline and self-management conditions, are presented in Figure 1.

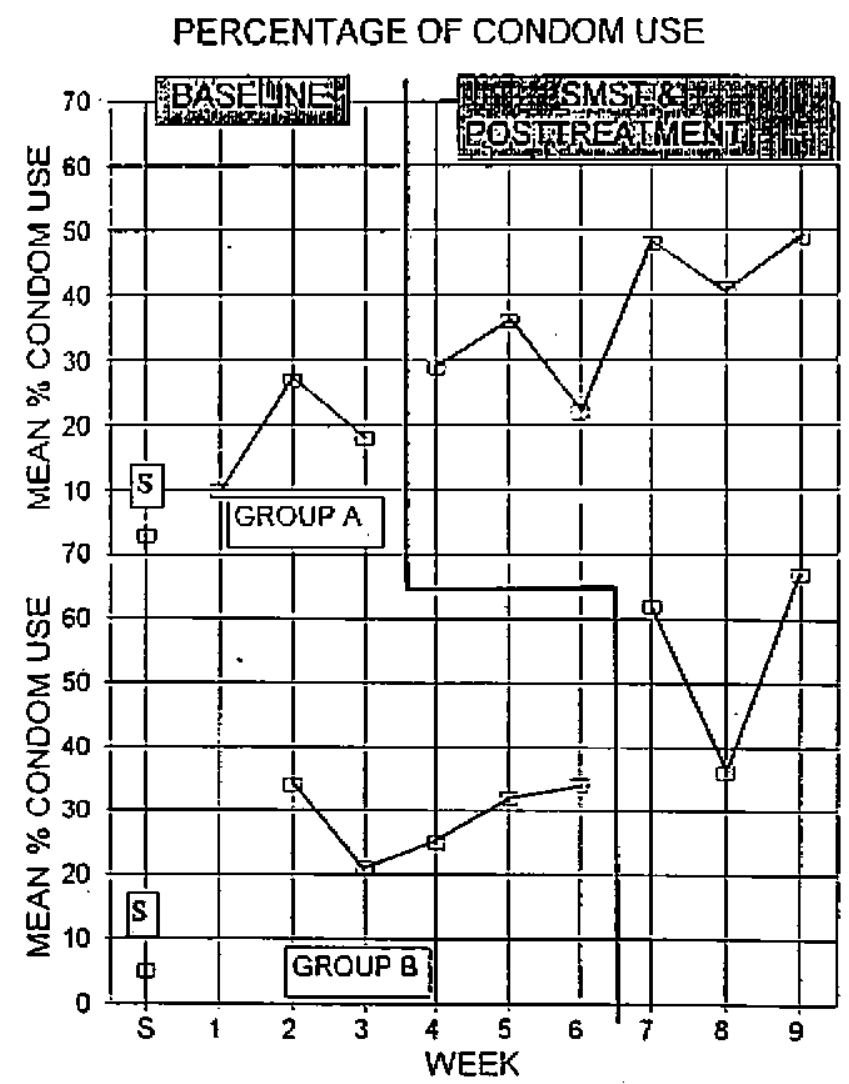

Figure 1: Groups A and B: Baseline and SMST \& Follow-up Weekly Means for Q2/Q1.

As this figure demonstrates, there were clear changes in the condom use responses of the participants related to the self-management training. The mean baseline percentage condom use for Group A was $18 \%$. This percentage doubled to $38 \%$ after training, with follow-up values in the 41 to $49 \%$ range. The change in condom use for Group B showed a similar increase, going from an average of $29 \%$ to $56 \%$ after self-management training. The groups' initial report of condom use for the month preceding the weekly reporting period is also indicated on the figure.

To determine whether any of these results were gender-specific, the combined data set was coded according to the gender of each subject, and analyses of variance (ANOVA) were performed for all of the variables. Main variables in the ANOVA were time period (pretreatment, posttreatment) and gender. As might be expected from the other results, the time period was a significant factor at an $\boldsymbol{a}=0.05$ level for variables condom use, acquisition and use/frequency (with p-values of 0.001 , 0.002 and 0.001 , respectively), but gender was not significant in any of the cases. 
Analysis of Outcomes

Although statistical analyses of the data are important, it is equally important to examine how individuals were affected by the program. In an attempt to do this, the data were reviewed, on a subject-by-subject basis, to develop a rationale for deciding whether or not an individual had shown behavior improvements. Assisting in this effort were the anecdotal comments submitted on many of the weekly reports, especially those related to a subject's reported decisions about condom use, or perceived risk of HIV infection.

From these reviews, the subjects were classified according to the degree of change evidenced by condom use, and then further classified by anecdotal comments and characteristics. These categories, and the number of subjects in each, are summarized in Table 2 .

\section{Table 2. Assessment of Study Outcomes}

\begin{tabular}{|c|c|c|c|}
\hline $\begin{array}{l}\text { Outcome } \\
\text { Category }\end{array}$ & $\begin{array}{l}\text { Number of } \\
\text { Subjects }\end{array}$ & $\begin{array}{l}\text { Description of } \\
\text { Outcome Subcategory }\end{array}$ & $\begin{array}{l}\text { Number } \\
\text { of } \\
\text { Subjects }\end{array}$ \\
\hline \multirow[t]{2}{*}{$\begin{array}{l}\text { Excellent } \\
\text { Outcome }\end{array}$} & \multirow{2}{*}{20} & $\begin{array}{l}100 \% \text { condom use reported by end } \\
\text { of study; were tested for HIV or } \\
\text { planned to be. }\end{array}$ & 5 \\
\hline & & $\begin{array}{l}100 \% \text { condom use reported by end } \\
\text { of study. }\end{array}$ & 15 \\
\hline \multirow{6}{*}{$\begin{array}{l}\text { Good/fair } \\
\text { Outcome }\end{array}$} & \multirow{6}{*}{18} & $\begin{array}{l}\text { No condom use, but cited reason } \\
\text { was total monogamy plus negative } \\
\text { HIV test results. }\end{array}$ & 4 \\
\hline & & $\begin{array}{l}\text { Inconsistent condom use, but cited } \\
\text { reason was negative HIV test } \\
\text { results. }\end{array}$ & 3 \\
\hline & & $\begin{array}{l}\text { Inconsistent condom use, but cited } \\
\text { reason was total monogamy. }\end{array}$ & 1 \\
\hline & & $\begin{array}{l}\text { Inconsistent condom use, but cited } \\
\text { reason was HIV testing (no results } \\
\text { yet) or plans for testing. }\end{array}$ & 7 \\
\hline & & $\begin{array}{l}\text { Abstinent throughout entire study; } \\
\text { planned to be tested. }\end{array}$ & 1 \\
\hline & & Abstinent throughout entire study. & 2 \\
\hline \multirow{2}{*}{$\begin{array}{l}\text { Poor } \\
\text { Outcome }\end{array}$} & \multirow{2}{*}{13} & $\begin{array}{l}\text { Increased but inconsistent condom } \\
\text { use. }\end{array}$ & 8 \\
\hline & & Dropped out of study. & 5 \\
\hline
\end{tabular}


Out of the total of 51 subjects who began the study, 20 had reportedly gone to $100 \%$ condom use by the final week, and 5 of these had been prompted to obtain HIV testing.

Another 18 subjects reported little or no change in condom use, but provided a written justification for the lack of change. Of these 18, 7 reported either total abstinence or in a monogamous relationship with negative HIV test results for both partners, and the 11 others reported either monogamy with no testing, or HIV testing. The remaining 13 subjects could be classified as failures, because they either dropped out of the study or showed no positive changes whatsoever, with no written justification for the lack of change.

\section{Evaluation of Pre-test and Post-test Results}

For the 46 subjects who completed the study, the raw pre-test and post-test data were compiled and converted into subscale and composite scores for the three test

Table 3. Comparision of Pre-test and Post-test Means

\begin{tabular}{|c|c|c|c|c|c|}
\hline \multirow{2}{*}{$\begin{array}{l}\text { Variable Name } \\
\text { (Subscale or } \\
\text { Composite) }\end{array}$} & \multicolumn{2}{|c|}{ Pre-test Statistics } & \multicolumn{2}{|c|}{ Post-test Statistics } & \multirow{2}{*}{$\begin{array}{l}\text { P-Values for } \\
\text { Wilcoxon } \\
\text { Signed Rank } \\
\text { Test }\end{array}$} \\
\hline & Mean & $\begin{array}{l}\text { Std Dev } \\
\text { (SD) }\end{array}$ & $\begin{array}{l}\text { Mean } \\
\text { (M) }\end{array}$ & $\begin{array}{c}\text { Std Dev } \\
\text { (SD) }\end{array}$ & \\
\hline FV & 19.87 & 4.52 & 22.98 & 3.49 & $<0.005^{*}$ \\
\hline FI & 13.78 & 3.48 & 15.70 & 3.10 & $<0.005 *$ \\
\hline \multirow[t]{2}{*}{ FSE } & 21.24 & 3.21 & 22.43 & 2.05 & $<0.007^{*}$ \\
\hline & $\mathbf{5 2 . 5 7}$ & 8.61 & 60.48 & 5.33 & $<0.005^{*}$ \\
\hline CE & 34.96 & 13.34 & 39.26 & 10.86 & $<0.009 *$ \\
\hline $\mathrm{CsC}$ & 28.59 & 11.47 & 40.37 & 9.35 & $<0.005^{*}$ \\
\hline CGA & 48.89 & 4.12 & 51.56 & 3.58 & $<\mathrm{0.005}^{*}$ \\
\hline CPRSK & 29.98 & 5.67 & 32.38 & 4.94 & $<0.005 *$ \\
\hline CIN & 21.30 & 3.90 & 21.91 & 3.94 & $>0.050$ \\
\hline CPROM & 15.30 & 3.54 & 17.09 & 2.13 & $<0.005^{*}$ \\
\hline CRS & 15.89 & 6.28 & 21.61 & 6.31 & $<0.005 *$ \\
\hline SCNOW & 21.00 & 2.86 & 21.24 & 3.56 & $>\mathbf{0 . 0 5 0}$ \\
\hline SCNEW & 8.52 & 2.47 & 9.65 & 2.55 & $<0.005^{*}$ \\
\hline FСOMP & 54.89 & 7.48 & 61.11 & 6.02 & $<0.005^{*}$ \\
\hline ССОМР & 246.48 & 36.57 & 284.65 & 31.58 & $<0.005^{*}$ \\
\hline SCOMP & 29.68 & 4.13 & 30.84 & 4.51 & $<0.010 *$ \\
\hline
\end{tabular}




\section{HORN \& BRIGHAM}

instruments. Using a Wilcoxon Signed Rank test, with the paired values of pre-test and post-test scores for each subject, the hypothesis thath was tested versus the alternative hypothesis for all of these test scores. The alternative hypothesis was formulated to see if there had been a significant positive increase in any of the subscale or composite scores.

Table 3 gives the summary statistics for the scores as well as the results of the Wilcoxon Signed Rank tests. For the 16 subscale and composite scores on the FABS, $\mathrm{CAS}$, and SC instruments, the null hypothesis $(/ \mathbf{n},=/ \boldsymbol{x})$ was rejected at the $\boldsymbol{a}=$ 0.05 level for every score but two: CIN (CAS Inhibition Subscale) and SCNOW (Sexual Communication, Current Partner Subscale). In addition, for every single case, the mean scores increased from the pre-test to the post-test.

Finally, the data were divided by gender, and Wilcoxon Rank Sum tests were performed to compare the male and female scores on each pre-test and post-test subscale. There were no significant gender-related differences between the male and female scores.

\section{Discussion}

The major hypothesis of this study was that a self-management skill training program would produce increased condom use and improved sexual communication between partners in a group of sexually active, at-risk, heterosexual college students. These outcomes have been emphasized by other researchers (DiClemente, 1991; Hearst \& Hulley, 1988; Valdiserri et al., 1988; ) as essential goals of AIDS risk reduction programs.

In terms of condom use at the initial screening, the original group of 51 subjects reported a condom-use frequency of slightly less than $4 \%$ during the previous month. Approximately $76 \%$ indicated no use whatsoever, and no subject reported consistently using condoms in the past. When the study ended, the percentage of reported use had risen to more than $50 \%$. Based on all the weekly self-monitoring data, mean condom-use frequency increased significantly (ap-value of 0.0003) from $23 \%$ during the pretreatment period to $50 \%$ in posttreatment. These results are also consistent with the changes in the reported actual number of times condoms had been used, rather than their use expressed as a percentage. For this variable, mean weekly use more than doubled from pre- to posttreatment, increasing from 0.27 to 0.68 times (p-value $=0.0002$ ). In addition, the reported purchase or other acquisition of condoms increased significantly $(\mathrm{p}$-value $=0.001$ ) over the study duration, again more than doubling compared to the pretreatment period.

This pattern of results was also observed independently for each group. All three of the condom-use and condom purchase variables showed significant increases for Groups A and B, regardless if the data are examined separately by group or combined into a single set. Additionally, these results are not affected by subject gender, as determined by ANOVA tests with gender as a main factor in the variable responses.

Similarly, the participants reported significantly improved sexual communication with their partners $(\mathrm{p}<.05)$. The importance of this observation, however, is difficult to assess because the initial scores on these measures were quite high despite 
reported high frequencies of unprotected sex and other high risk behaviors. Clearly, the role of sexual communication in health protective behavior needs to be further investigated.

From the perspective of the results related to attitudes and beliefs, every subscale and composite score from three test instruments increased from pre-test to post-test, with all but two of these increases significant at the $\boldsymbol{a}=0.05$ level. In addition to the SCNOW subscale, the CIN subscale (personal inhibitions about condom use) did not increase significantly. This is also, however, a subscale score that was originally very high on the pre-test, with accordingly little room for improvement.

Of all the 13 subscales examined, the lowest pre-test scores are seen in the CSC (self-control), CE (effect of condoms on sexual experience), CRS (relationship safety), and FI (intent to use condoms) subscales. Two of these (CSC and CRS), however, had the largest percentage change from pre-test to post-test, helping to demonstrate the effectiveness of a SMST approach that had targeted self-control and knowledge of one's sexual partner as key intervention elements. Unfortunately, the post-test scores for CE effect on sexual experience, and FI intent to use condoms, remained low, compared to other subscales, despite the fact that they had increased significantly. These low scores are consistent with prior research indicating that this population has a negative attitude towards condom use, believing that it decreases sexual pleasure (Sacco et al., 1991).

An issue of concern in research investigating private behavior is the correspondence between the participants' verbal reports of behavior and their actual behavior. In the present study, it was necessary to rely on the subjects' verbal reports because it was not possible to directly observe the key target responses. The obvious question is: "Are those reports valid?" Within the context of the present research, there are a number of reasons for having some confidence in the accuracy of the reports. First, the students mailed their reports directly to the principal investigator. Therefore, the program instructors had no knowledge of the students' reports, and the students had no obvious reason to adjust their responses to please the instructors. Second, the responses were monitored constantly and reported weekly. This pattern of regular reporting has been demonstrated to improve the accuracy of self-reports (Babor, Brown \& Del Boca, 1990; Baker \& Brandon, 1990; Barlow, Hayes \& Nelson, 1984). Further, the reporting form had a "comments" section where participants could provide additional information about their behavior. Well over half of the forms included such information which often furnished detailed explanations of the person's behavior. Two other sources of supporting evidence come from the homework assignments such as purchasing condoms or talking to a friend about AIDS where participants were asked to provide some form of documentation of their behavior. In those cases, there was good correspondence between the two types of data. Finally, in regard to the reported HIV testing, because of good relations with local health clinics, it was possible to confirm that several people had given the program as the reason they were being tested.

Clearly, none of these arguments fully dispels our uneasiness about the verbal nature of the data. Nonetheless, the evidence is consistent with the reported changes in private behavior and increases our confidence that the majority of the self-reports 


\section{HORN \& BRIGHAM}

were valid. We are currently working to develop more systematic forms of nonintrusive supporting evidence and as far as possible, eliminate factors in the program that might lead to falsification of the self-reported data.

To review, this group of 51 subjects reported significant behavioral and attitudinal changes, following the 3-week, 6 hour, SMST intervention program. These results should be examined within the context of other related research efforts. As previously discussed, the few prior studies of sexually active heterosexuals have generally focused on behavior predictors, risk-factors, and beliefs or attitudes (Kelly $\&$ Murphy, 1992), and not on intervention effects on behavior. However, these studies have provided important clues regarding the factors and personal skills that may influence behavior, including self-efficacy and peer opinion (Wulfert \& Wan, 1993), assertiveness (Kelly et al., 1989), sexual communication (DiClemente, 1991), vulnerability awareness (Kelly et al., 1990), condom-use skills (Blonna et al., 1991), self-control skills (Sacco et al., 1991), and evaluation of environmental antecedents (Brigham, 1989; Kelly \& St. Lawrence, 1987).

In studies where didactic, behavioral, or cognitive-behavioral intervention programs have been used, nearly all of the reported successes have been with the homosexual community (primarily gay men in epicenters of the AIDS epidemic). Coates (1990) and Kelly et al. (1993) summarized many of these studies, and concluded that significant short-term behavior changes had been demonstrated with the interventions. Within the heterosexual population, however, there have been far

fewer reported interventions for AIDS risk reduction, and the previous interventions have been, for the most part, unsuccessful in altering risky behaviors (Baldwin \& Baldwin, 1988; Goertzel \& Bluebond-Langner, 1991; Kegeles, Adler, \& Irwin, 1988). In most of these cited cases, however, intervention was didactic, emphasizing AIDS education, modes of HIV transmission, and STD risk statistics.

Nearly all of these successful behavioral interventions, whether with hetero- or homosexual groups, fall within the self-management model used in this current study. This model utilizes behavior analytic principles to modify the individual's behavior in conjunction with his or her environment (Brigham, 1989; Kelly et al., 1987), and targets specific skill areas that increase the probability of reinforcement of the desired behavioral responses. These skills include many of those previously cited from other research as key predictors of both behavior and attitudes.

The SMST framework developed for the current study consists of the goals and processes necessary to address knowledge and skills that have been linked by the cited literature to behavioral changes. In addition, a key focus of the new approach is the individual action plan (IAP). Instead of a didactic procedure, where subjects were given a set of behavioral expectations from an external source, they developed their own-personally, and within the group format. This required a consideration of their own situation and behavior patterns, their own values and goals, and their own behavior/environment interactions. Based on this analysis, each person then stated, in writing, an explicit plan for managing future behaviors consistent with personal values and goals.

Although writing a plan does not guarantee compliance, it does increase the probability that an individual will modify his or her behavior, for several reasons. First, the plan is a prerequisite to systematic behavior change because it provides the 
guide to the new behavior. Second, the process of plan preparation makes the individual more aware of his or her current behavior patterns and any changes that may be necessary. This in turn increases the salience of the desired responses, making them more likely to occur. Third, because the IAP was developed by, and not for, the individual, each person gains a sense of "ownership" in his or her plan. This element of ownership, or a personal stake in the goals that have been established, has been viewed by Heckhausen and Gollwitzer (1987) as essential in developing a relationship between the cognitive aspects of a goal or plan, and the desired behavior over time. Fourth, because subjects became personally involved in activities such as condom comparison, the attitudes that were developed and expressed in discussion and in their written plan also became their own. This concept of direct experience, specifically with hands-on activities, is seen by Winter and Goldy (1993) as being particularly effective in enhancing attitude-behavior correspondence. Finally, putting a plan in writing and then discussing it in a group format is a form of commitment response which psychologically makes it more difficult not to change.

A second procedural difference between this study and many others was the inclusion of both males and females in each training group. This format of groups with both genders, where the subjects did not know each other prior to treatment, provided an excellent in vivo mimic of real-life situations likely to be experienced by the participants. It provided the opportunity to practice new skills in a safe, but realistic setting; receive group feedback to revise and improve these skills; and then finally to transfer the skills to real-life partners and potential partners. The involvement of peers and peer norms has been found to be an important factor in causing and maintaining low-risk behaviors (Chesney, 1993). Overall, these group dynamics werejudged to be important to the study outcome, with peer pressure and public commitment to change probably affecting the actual compliance with these commitments.

A third major factor that distinguishes this study was the number of training sessions and the length of involvement between the group leaders and the subjects. Here the procedures consisted of a three-session, 6 hour format. In addition, some form of contact between the leaders and subjects was required over the 10-week period of weekly reports. In many cases, subjects were contacted by phone during the study to inform them about session times or to remind them that reports or tests were due. Occasionally, subjects would contact the group leaders by phone to discuss topics that had been covered during a training session. In total, this resulted in a continuing interaction between the subjects and the group of leaders for a period of approximately 3 months. All of these factors appear to have contributed to the results of the present study, but clearly, they will need to be examined experimentally to ascertain the contribution of each to the observed results.

Similarly, because it was not possible to do a complete follow-up check, it is impossible to state with confidence that the reported changes in participants' behavior were permanent. However, the type of behavior change observed in this study requiring new skills and considerable effort are more likely to be maintained (Kazdin, 1994). For instance, the procedures and target behaviors of this study closely resemble those of Kelly et al., (1989) who reported high levels of behavior 


\section{HORN \& BRIGHAM}

change sustained over a 16-month period. As a consequence, there are good reasons to believe the changes found in this study will persist, but it will be necessary to systematically follow the participants in future projects to determine how well their new patterns of behavior are maintained.

Finally, the subjects in the present study were not very representative of the general population of adolescents and young adults. They were all Caucasian college students who were engaging in high risk sexual activities and seldom using condoms. They were, in fact, selected for the project because this pattern of behavior has been very difficult to change (Blonna et al, 1991; Chesney, 1993; Strunin \& Hingson, 1989). Nonetheless, the degree to which any of these characteristics may have interacted with the program to produce positive changes is unknown and as a consequence, the generality of the findings is in doubt. Obviously, further research with more diverse populations is required to determine if the approach is broadly effective with groups having different ethnic backgrounds and sexual orientations. In conclusion, irrespective of the limitations of the present research, the results of this study suggest that instruction based on behavioral self-management principles and procedures can form the core of a systematic AIDS prevention program.

\section{REFERENCES}

Babor, T., Brown, J. \& Del Boca, F. (1990). Validity of self-reports in applied research on addictive behaviors: Fact or fiction? Behavioral Assessment, 12, 5-31.

Baker, T. \& Brandon, T. (1990). Validity of self-reports in basic research. Behavioral Assessment, 12, 33-51.

Baldwin, J.D., \& Baldwin, J.I. (1988). Factors affecting AIDS-related sexual risk-taking behavior among college students. The Journal of Sex Research, 25(2), 181-196. http://dx.doi.org/10.1080/00224498809551454

Barlow, D., Hayes, S. \& Nelson, R. (1984). The scientist practitioner. New York: Pergamon Press.

Baum, L., \& Weltman, S. (1989, November/December). AIDS on campus. Campus Voice Magazine, pp. 34-37.

Becker, M.H., \& Joseph, J.G. (1988). AIDS and behavioral change to reduce risk: A review. American Journal of Public Health, 78(4), 394-410. http://dx.doi.org/10.2105/AJPH.78.4.394

Biemiller, L. (1989, February 11). Colleges could play crucial role in halting spread of AIDS epidemic, public officials say. The Chronicle of Higher Education, pp. 1, 32.

Blonna, R., Hayden, Jr., \& Milcetic, J. (1991). Development of a classroom-based AIDS education program at a New Jersey state college. Journal of American College Health, 40, 95-96. http://dx.doi.org/10.1080/07448481.1991.9936262

Bowler, S., Sheon, A.R., D'Angelo, L.J., \& Vermund, S.H. (1992). HIV and AIDS among adolescents in the United States: Increasing risk in the 1990's. Journal of Adolescence, 15, 345-371. http://dx.doi.org/10.1016/0140-1971(92)90069-H

Brigham, T. (1982). Self-management: A radical behavior perspective. In P. Karoly \& F.H. Kanfer (Eds.), Self-management and behavior change from theory to practice (pp. 32-59). New York: Pergamon.

Brigham, T. (1989). Self-management for adolescents: A skills training program. New York: Guilford.

Campbell, D.T. \& Stanley, J.C. (1963). Experimental and quasi-experimental designs for research. Chicago: Rand-McNally.

Catania, J.A., Coates, T.J., Stall, R., Turner, H., Peterson, J., Hearst, N., Dolcini, M.M., Hudes, E., Gagnon, J., Wiley, J., \& Groves, R. (1992). Prevalence of AIDS-related risk factors and condom use in the United States. Science, 258, 1101-1106. http://dx.doi.org/10.1126/science.1439818

Catania, J.A., Dolcini, M.M., Coates, T.J., Kegeles, S.M., Greenblatt, R.M., Puckett, S., Corman, M., \& Miller, J. (1989). Predictors of condom use and multiple partnered sex among sexually-active adolescent women: Implications for AIDS-related health interventions. Journal of Sex Research, 26(4), 514-524. http://dx.doi.org/10.1080/00224498909551532

Centers for Disease Control (1993). HIV/AIDS surveillance: Year-end edition. Atlanta, GA: CDC.

Chesney, M.A. (1993). Health psychology in the 21st century: Acquired Immunodeficiency Syndrome as a harbinger of things to come. Health Psychology, 12(4), 259-268. http://dx.doi.org/10.1037/0278-6133.12.4.259 
Coates, T.J. (1990). Strategies for modifying sexual behavior for primary and secondary prevention of HIV disease. Journal of Consulting and Clinical Psychology, 58(1), 57-69. http://dx.doi.org/10.1037/0022-006X.58.1.57

DiClemente, R.J. (1991). Predictors of HIV-preventive sexual behavior in a high-risk adolescent population: The influence of perceived peer norms and sexual communication on incarcerated adolescents' consistent use of condoms. Journal of Adolescent Health, 12, 385-390. http://dx.doi.org/10.1016/0197-0070(91)90052-N

Fisher, J.D., \& Fisher, W.A. (1992). Changing AIDS risk behavior. Psychological Bulletin, 3, $455-474$. http://dx.doi.org/10.1037/0033-2909.111.3.455

Foster, J.D. (1988). Protection motivation theory: An examination of college students' AIDS-related beliefs and behaviors. Unpublished Master's Thesis. Washington State University, Pullman, WA.

Gayle, H.D., Keeling, R.P., Garcia-Tunon, M., Kilbourne, B.W., Narkanus, J.P., Ingram, F.R., Rogers, M.F., \& Curran, J.W. (1990). Prevalence of the human immunodeficiency virus among university students. The New England Journal of Medicine, 323(22), 1538-1541. http://dx.doi.org/10.1056/NEJM199011293232206

Goertzel, T., \& Bluebond-Langner, M. (1991). What is the impact of a campus AIDS education course? Journal of American College Health, 40(27), 87-92. http://dx.doi.org/10.1080/07448481.1991.9936261

Hearst, N., \& Hulley, S.B. (1988). Preventing the heterosexual spread of AIDS: Are we giving our patients our best advice? Journal of the American Medical Association, 259(16), 2428-2432. http://dx.doi.org/10.1001/jama.1988.03720160048029

Heckhausen, H., \& Gollwitzer, P.M. (1987). Thought contents and cognitive functioning in motivational versus volitional states of mind. Motivation and Emotion, 11, 101-120. http://dx.doi.org/10.1007/BF00992338

Hobfoll, S.E., Jackson, A.P., Lavin, J., Britton, P.J., \& Shepherd, J.B. (1994). Reducing inner-city women's AIDS risk activities: A study of single, pregnant women. Health Psychology, 13 (5), 397 ᄀ 403. http://dx.doi.org/10.1037/0278-6133.13.5.397

Kazdin, A.E. (1994). Behavior modification in applied settings. Pacific Grove, CA: Brooks/Cole Publishing Company.

Kegeles, S.M., Adler, N.E., \& Irwin, CE. (1988). Sexually active adolescents and condoms: Changes over one year in knowledge, attitudes, and use. American Journal of Public Health, 78(4), 460-461. http://dx.doi.org/10.2105/AJPH.78.4.460

Kelly, J.A., Murphy, D.A., Sikkema, K.J., \& Kalichman, S.C. (1993). Psychological interventions to prevent HTV infection are urgently needed. American Psychologist, 48(10), 1023-1034. http://dx.doi.org/10.1037/0003-066X.48.10.1023

Kelly, J.A., \& St. Lawrence, J.S. (1987). The prevention of AIDS: Roles for behavioral intervention. Scandinavian Journal of Behavior Therapy, 16, 15-19. http://dx.doi.org/10.1080/16506078709455778

Kelly, J.A., St. Lawrence, J.S., Brasfield, T.L., Lemke, A., Amedei, T., Roffman, R.E., Hood, H.V., Smith, J.E. Kilgore, H., \& McNeil, C. (1990). Psychological factors that predict AIDS precautionary behavior. Journal of Consulting and Clinical Psychology, 58, 117-120. http://dx.doi.org/10.1037/0022-006X.58.1.117

Kelly, J.A., St. Lawrence, J.S., Hood, J.V., \& Brasfield, T.L. (1989). Behavioral intervention to reduce AIDS risk activities. Journal of Consulting and Clinical Psychology, 57(1), 60-67. http://dx.doi.org/10.1037/0022-006X.57.1.60

McKusick, L., Horstman, W., \& Coates, T.J. (1985). AIDS and sexual behavior reported by gay men in San Francisco. American Journal of Public Health, 75, 493-496. http://dx.doi.org/10.2105/AJPH.75.5.493

Orr, D.P., Langefeld, CD., Katz, B.P., Caine, V.A., Dias, P., Blythe, M., \& Jones, R.B. (1992). Factors associated with condom use among sexually active female adolescents. Journal of Pediatrics, 120, 311-317. http://dx.doi.org/10.1016/S0022-3476(05)80453-6

Rehnberg, T. (1991). The effect of a health belief intervention of safer sex practices in a sexually active female college population. Unpublished dissertation, Washington State University, Pullman, WA.

Sacco, W.P., Levine, B., Reed, D.L., \& Thompson, K. (1991). Attitudes about condom use and AIDSrelevant behavior: Their factor structure and relation to condom use. Psychological Assessment: Journal of Consulting and Clinical Psychology, 3(2), 265-272. http://dx.doi.org/10.1037/1040-3590.3.2.265

Shulkin, J.J., Mayer, J.A., Wessel, L.G., DeMoor, C, Elder, J.P., \& Franzini, L.R. (1991). Effects of a peer-led AIDS intervention with university students. Journal of American College Health, 40(2), 75-79. http://dx.doi.org/10.1080/07448481.1991.9936259

Strunin, L., \& Hingston, R. (1987). AIDS and adolescents: Knowledge, beliefs, attitudes, and behaviors. Paper presented at the 3rd International Conference on AIDS, Washington, D.C. Valdiserri, R.O., Lyter, D., Leviton, L.C., Callahan, CM., Kingsley, L.A., \& Rinaldo, CR. (1988). Variables influencing condom use in a cohort of gay and bisexual men. American Journal of Public Health, 78(7), 801-805.

Winter, L., \& Goldy, A.S. (1993). Effects of prebehavioral cognitive work on adolescents' acceptance of condoms. Health Psychology, 12(4), 308-312. http://dx.doi.org/10.1037/0278-6133.12.4.308

Wulfert, E., \& Wan, C. (1993). Condom use: A self-efficacy model. Health Psychology, 12(5), $346-353$. http://dx.doi.org/10.1037/0278-6133.12.5.346 